\title{
Antagonistic Gcn5-Hda1 interactions revealed by mutations to the Anaphase Promoting Complex in yeast
}

\author{
Azharul Islam, Emma L Turner, Johannes Menzel, Mackenzie E Malo and Troy AA Harkness
}

\begin{abstract}
Background: Histone post-translational modifications are critical for gene expression and cell viability. A broad spectrum of histone lysine residues have been identified in yeast that are targeted by a variety of modifying enzymes. However, the regulation and interaction of these enzymes remains relatively uncharacterized. Previously we demonstrated that deletion of either the histone acetyltransferase (HAT) GCN5 or the histone deacetylase (HDAC) HDA1 exacerbated the temperature sensitive (ts) mutant phenotype of the Anaphase Promoting Complex (APC) $a p c 5^{C A}$ allele. Here, the $a p c 5^{C A}$ mutant background is used to study a previously uncharacterized functional antagonistic genetic interaction between Gcn5 and Hda1 that is not detected in APC5 cells.
\end{abstract}

Results: Using Northerns, Westerns, reverse transcriptase PCR (rtPCR), chromatin immunoprecipitation (ChIP), and mutant phenotype suppression analysis, we observed that Hda1 and Gcn5 appear to compete for recruitment to promoters. We observed that the presence of Hda1 can partially occlude the binding of Gcn5 to the same promoter. Occlusion of Gcn5 recruitment to these promoters involved Hda1 and Tup1. Using sequential ChIP we show that Hda1 and Tup1 likely form complexes at these promoters, and that complex formation can be increased by deleting GCN5.

Conclusions: Our data suggests large Gcn5 and Hda1 containing complexes may compete for space on promoters that utilize the Ssn6/Tup1 repressor complex. We predict that in apc5 ${ }^{C A}$ cells the accumulation of an APC target may compensate for the loss of both GCN5 and HDA1.

\section{Background}

Eukaryotic genetic information is packaged into chromatin, a highly organized and dynamic protein-DNA complex. The fundamental unit of chromatin, the nucleosome, is an octameric structure composed of two copies of each of the four core histones (an H3/H4 tetramer and two $\mathrm{H} 2 \mathrm{~A} / \mathrm{H} 2 \mathrm{~B}$ dimers), surrounded by approximately 146 bp of DNA [1,2]. Many cellular processes depend on modifications of both DNA and histones within nucleosomes [3,4]. Modification of chromatin by histone acetyltransferases (HATs) and histone deacetylases (HDACs) play key roles in transcriptional regulation [5-9]. Post-translational acetylation of the highly conserved lysines within the $\mathrm{N}$-terminal tail domains of the core histones is strongly correlated with

\footnotetext{
* Correspondence: troy.harkness@usask.ca

Department of Anatomy and Cell Biology, University of Saskatchewan, Saskatoon, SK, S7N 5E5, Canada
}

transcriptional activation [5,10]. Although the precise mechanisms by which histone acetylation alters transcription are poorly understood [9-12], there is tremendous pressure to understand these mechanisms, as impaired histone modification is linked to many disease states [13].

The study of HAT and HDAC recruitment to promoters and their interaction with activators and repressors are essential for a better understanding of gene regulation. HATs and HDACs modify histones enzymatically throughout the genome [14]. Histone acetylation potentially regulates transcription by manipulating the higherorder folding properties of the chromatin fiber [15-17]. General control nonderepressible 5 (Gcn5) [18] was the first identified HAT and exists as the catalytic subunit in multiple high molecular weight complexes in yeast, including SAGA (Spt-Ada-Gcn5-Acetyltransferase), SLIK (SAGA-like), ADA (transcriptional ADAaptor), 
and the smaller HAT-A2 complex [19-23]. As part of the evolutionarily conserved SAGA complex, Gcn5 predominantly acetylates nucleosomal H3 lysines K9, K18, and K27 [24]. Defects in human SAGA subunits are associated with multiple disorders, including neurological diseases and aggressive cancers [25,26]. Gcn5 is a direct target for recruitment by transcriptional activators in vitro $[27,28]$ and in vivo [29], which results in the acetylation of nearby histones [10]. Elongation of the transcripts initiated by Gen5-containing complexes is carried out by the Elongator complex, which utilizes Elp3 as its primary HAT [30,31]. Cell cycle specific roles for Gcn5 have been reported, as recruitment of Gcn5 to a set of genes that are expressed in late mitosis requires SWI/SNF remodelling activity [32]. Furthermore, Gcn5 displays an overlapping pattern of localization with several HDACs $[24,33,34]$. Acetylation microarrays have shown that Rpd3 and Hda1 are the principal HDACs in yeast, affecting numerous promoters throughout the genome with little overlap between promoters $[10,35]$. Hda1, an evolutionary conserved HDAC, which deacetylates mainly histones $\mathrm{H} 2 \mathrm{~B}$ and $\mathrm{H} 3$ [36,37], is recruited to promoters via utilization of different Tup1/Ssn6 domains [38-40], resulting in local deacetylation. HDAC recruitment may form a positive feedback loop to repress transcription locally and facilitate the spreading of Tup1 into adjacent regions [41]. Tup1-mediated repression requires the deacetylation of histones within promoters [42-44], which may require direct recruitment of HDACs $[36,45,46]$. Overall, the mechanisms of Tup1/Ssn6-mediated transcriptional repression can be classified into 3 classes: (i) direct interaction with the activator; (ii) repression by changing chromatin structure; and (iii) interaction with the general transcription machinery $[47,48]$. It appears that different groups of genes have developed different strategies to utilize Tup1/Ssn6, enabling it to function as a global repressor.

Our work has linked the Anaphase Promoting Complex (APC), an evolutionarily conserved 13 subunit complex in yeast that is critical for mitotic progression and G1 maintenance [49-52], with chromatin assembly and histone acetylation through genetic interactions with chromatin assembly factor (CAF), HAT and HDAC mutants [53-57]. The APC is a ubiquitin-protein ligase (E3) that targets proteins that block the initiation of anaphase (Pds1) and mitotic exit (Clb2) for degradation. Various regulators govern APC activity in positive and negative manners, from phosphorylation and transcriptional control of APC subunits, to sequestration of APC activators [58-63]. For example, protein kinase A (a complex of Bcy1, Tpk1, Tpk2 and Tpk3) and Mad2 inhibit APC activity through phosphorylation and subunit sequestration, respectively. Activating phosphorylation is supplied by the polo-like kinase (Cdc5) and
Cdc28. Furthermore, Cdc20, inhibited by a Mad2dependent mechanism, binds and activates the APC to promote the metaphase/anaphase transition, while Cdh1, another APC-binding partner, drives APC-dependent mitotic exit. Previous studies by our group have expanded the APC's functional repertoire by showing that the mutant APC subunit allele, apc5 ${ }^{C A}$ [54], genetically interacted with deletions of the HAT encoding genes GCN5 and ELP3 [57]. Strains harboring the apc5 ${ }^{C A}$ gcn5 5 or the apc5 ${ }^{C A}$ elp $3 \Delta$ mutations had severely restricted growth at elevated temperatures compared to the single mutants. This interaction implies that the APC and these HATs positively interact, but a negative feedback loop appears apparent, as G1-specific Gon 5 instability was reduced in APC mutant cells. An additional synergistic genetic interaction between $h d a 1 \Delta$ and $a p c 5^{C A}$ was also observed, suggesting that the APC interacts positively with the HDAC Hda1 [57]. The study presented here focuses on a novel antagonistic relationship between $g c n 5 \Delta$ and $h d a 1 \Delta$ that is revealed in $a p c 5^{C A}$, but not APC5 cells. We provide further evidence that the APC works with multiple histone modifiers to drive cell cycle progression.

\section{Results}

\section{gcn5 $5 /$ hda $1 \Delta$ interactions revealed in an APC mutant background}

In a recent screen, we identified HAT $(g c n 5 \Delta)$ and HDAC ( $h d a 1 \Delta)$ deletions that severely impacted the $a p c 5^{C A}$ (chromatin assembly defective) $[54,57]$ temperature sensitive $(t s)$ phenotype, indicating that both proteins have a positive influence on Anaphase Promoting Complex (APC) activity. The $a p c 5^{C A}$ mutation was identified in a chromatin assembly mutant screen; the allele contains an AT deletion altering amino acid 12, which created an in-frame stop codon 12 amino acids further along [54]. We recently observed that the apc5 $5^{\mathrm{CA}}$-TAP (Tandem Affinity Protein purification) protein migrates faster, with less intensity, than the wild type Apc5-TAP by SDS-PAGE, indicating that $a p c 5^{C A}$ encodes an Nterminal truncation (data not shown). Here we show that deletion of $H D A 1$ in $g c n 5 \Delta$ cells had no apparent effect (Figure 1A), whereas deletion of $H D A 1$ in $a p c 5^{C A}$ $g c n 5 \Delta$ cells improved ts growth. The apc5 $5^{C A}$ background therefore allowed the study of a previously uncharacterized antagonistic interaction in yeast between Gcn 5 and Hda1. Plant GCN5 was also found to interact antagonistically with HD1, the Hda1 orthologue, to regulate lightresponsive gene expression [64], but mechanisms remained undetermined.

To examine whether Hda1 positively interacted with the APC, we expressed galactose driven $H D A 1$ carrying a C-terminal HA tag $\left(G A L_{p r o} H D A 1-H A\right)$ at low levels in WT, $a p c 5^{C A}$ and $g c n 5 \Delta$ cells by using glucose as a 
A

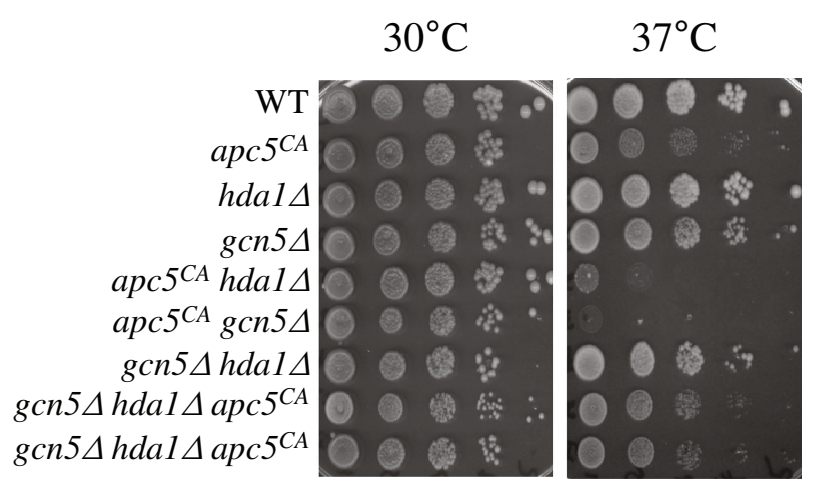

B

\section{$30^{\circ} \mathrm{C}$ Glucose}
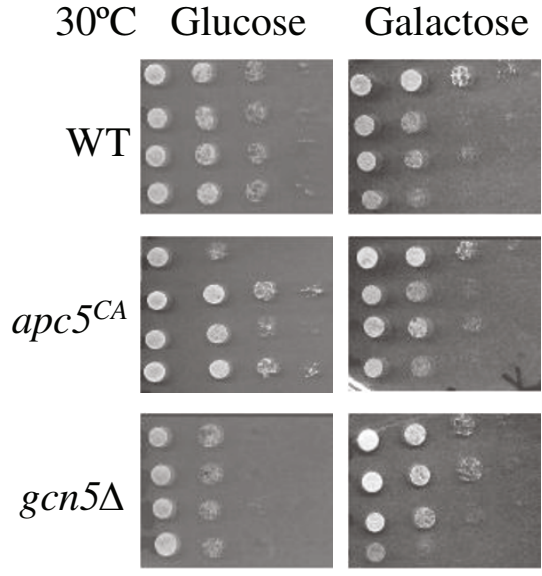

empty vector

$G A L_{\text {pro }} A P C 5$

$G A L_{p r o}^{\text {pro }} H P A 2$

GAL ${ }_{\text {pro }} H D A 1$

empty vector

$G A L_{\text {pro }} A P C 5$

$G A L_{p r o} H P A 2$

$G A L_{p r o} H D A 1$

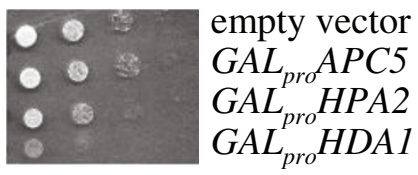

C

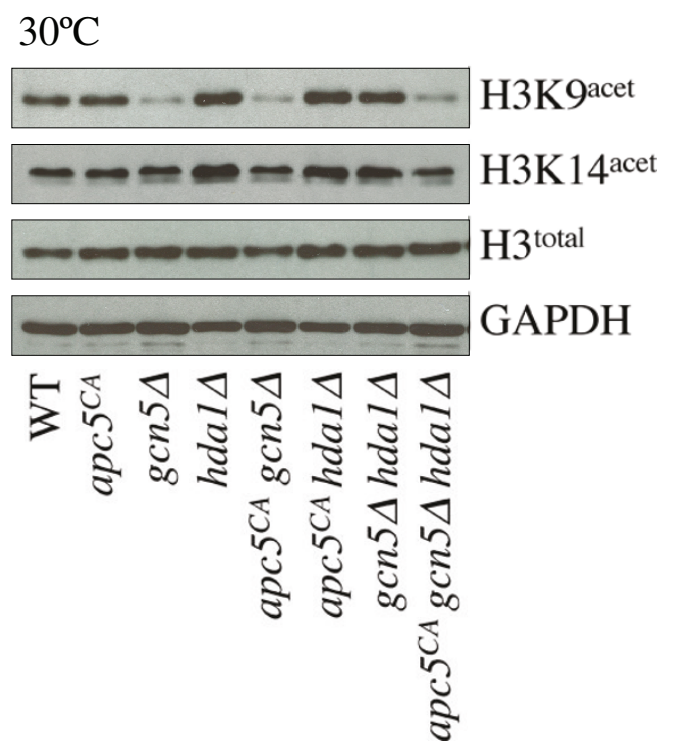

Figure 1 Mutation to the APC subunit Apc5 reveals antagonistic interactions between Gcn5 and Hda1. (A) Serial 10-fold dilutions of each strain were spotted onto YPD plates from left to right and incubated at the temperatures shown. (B) Serial dilutions using strains expressing the indicated plasmids were spotted onto SD-ura plates containing either $2 \%$ glucose or $2 \%$ galactose, and grown at $30^{\circ} \mathrm{C}$ for 2 and 3 days, respectively. (C) Protein lysates were prepared from the mutants shown and characterized by Westerns using the antibodies indicated. Antibodies against GAPDH were used as load controls.

carbon source (Figure 1B). Recently, we observed that mRNA levels of $G A L_{\text {pro }} G C N 5-H A$ were elevated 100-fold when grown on $2 \%$ glucose and 900 -fold when grown on $2 \%$ galactose [57]. However, Gcn5-HA protein expression remained low even though GCN5-HA mRNA was 100fold elevated when grown on $2 \%$ glucose. As shown with GCN5 [57], low-level GAL pro $_{\text {HDA }}$ 1-HA expression improved $a p c 5^{C A}$ growth (Figure 1B). This is not necessarily a general feature of histone modifying proteins, as deletion or overexpression of the HAT HPA2 had little effect on $a p c 5^{C A}$ cells (Figure 1B) [57]. Although the yeast $\mathrm{Hpa} 2$ has not yet been shown to acetylate histones in vivo, a bacterial acetyltransferase that does acetylate eukaryotic histones is most closely related to $\mathrm{Hpa} 2$, and $\mathrm{Hpa} 2$ does acetylate $\mathrm{H} 3$ in vitro $[65,66]$. Moreover, Hpa2 appears to be active, as overexpression reduces growth of $g c n 5 \Delta$ cells, whereas expression on glucose improves growth of $a p c 5^{C A}$ cells (Figure 1B).

A further connection between Gcn5 and Apc5 was observed by the rescue of $G A L_{p r o} A P C 5-H A$ overexpression toxicity by deletion of GCN5 (Figure 1B). It is unlikely that Apc5 protein levels induced from the $G A L$ promoter are compromised in $g c n 5 \Delta$ cells, as expression of HPA2 and HDA1 from the GAL promoter reduces 
gcn5 5 growth. Overexpression of APC5 from the CUP1 promoter also reduced yeast replicative lifespan [60]. Rescue of APC5 toxicity by GCN5 deletion is consistent with our recently proposed hypothesis that Gcn 5 is required for APC activity, and may provide an explanation as to why GCN5 [57] and HDA1 (Figure 1B) overexpression is toxic, considering that overabundance of Apc5 is detrimental to cells.

Next, we asked whether mutations to APC5 influenced acetylation of histone $\mathrm{H} 3$ lysine 9 or 14 (H3K9/14) in $g c n 5 \Delta$ and $h d a 1 \Delta$ cells. Gcn 5 appears to play a greater role on H3K9, compared to H3K14, whereas loss of HDA1 results in increased acetylation of both H3K9 and H3K14 (Figure 1C). The apc5 ${ }^{C A}$ background did not change the acetylation status of H3K9/14 in $g c n 5 \Delta$ or $h d a 1 \Delta$ cells, suggesting the $a p c 5^{C A}$ background may be revealing an effect other than global histone $\mathrm{H} 3$ acetylation. H3K9Ac was reduced in $g c n 5 \Delta$, apc $5^{C A} g c n 5 \Delta$ and apc5 ${ }^{C A} g c n 5 \Delta$ hda $1 \Delta$ cells, but not in $g c n 5 \Delta$ hda $1 \Delta$ cells. The ability to acetylate H3K9 in $g c n 5 \Delta$ hda1 $\Delta$ cells indicates that on a global level, other HATs can use $\mathrm{H} 3 \mathrm{~K} 9$ as a substrate. However, at the gene level, deletion of GCN5 was previously shown to reverse histone hyperacetylation at the $\mathrm{PHO} 5$ promoter when $H D A 1$ was deleted [67]. Therefore, we tested whether transcript levels are influenced by $a p c 5^{C A}$ in $g c n 5 \Delta$ or hda1 $\Delta$ cells.

The $a p c 5^{C A}$ allele increases transcript levels in hda $1 \Delta$ cells Since the $a p c 5^{C A}$ allele had little effect on global histone H3K9/14 acetylation, we asked whether individual gene transcripts were altered. We chose to study several genes involved in APC function, as altered expression of APC regulators may underlie the observed growth phenotypes. Thus, we performed Northern and reverse transcriptase PCR (rtPCR) experiments to determine expression of CDC20, PDS1, BCY1 and MAD2. Cdc20 plays a positive role in APC activity, whereas Pds1, Bcy1 and Mad2 have a negative impact [58-63]. Northerns (Figure 2A) and rtPCR (data not shown) both show that compared to RDN1, expression of the tested transcripts were reduced in $g c n 5 \Delta$ cells, especially at $37^{\circ} \mathrm{C}$, whereas transcripts in hda1 $\Delta$ cells were relatively unimpaired. The bands from 2 Northerns and 2 rtPCR experiments were scanned, quantified and averaged, with the expression of each gene for each experiment normalized to RDN1. This number is relative to expression in the wild type strain, which was set to 1 (Figures $2 \mathrm{~B}, \mathrm{C}$ ). Although previous microarray analyses in $g c n 5 \Delta$ and $h d a 1 \Delta$ cells did not identify these genes $[68,69]$, the approximate 2fold decrease in transcript levels in $g c n 5 \Delta$ cells (Figure 2C) suggests Gcn 5 is involved in expression of the tested genes. However, while the $a p c 5^{C A}$ allele had no apparent effect on transcript levels in $g c n 5 \Delta$ cells, in $a p c 5^{C A} h d a 1 \triangle$ cells, $B C Y 1$ transcripts (Figure 2B) and PDS1 transcripts (Figure $2 \mathrm{C}$ ) were clearly elevated. The loss of this effect in the triple mutant suggests Gcn5 may be required for elevated transcription in $a p c 5^{C A}$ hda1 $\Delta$ cells.

\section{Increased PDS1 transcripts in apc5 ${ }^{C A}$ hda1 1 cells correlates with increased promoter acetylation}

Our data suggests the $a p c 5^{C A}$ allele enhances the transcript levels of some of the tested genes in hda1s cells. We next tested whether promoter acetylation of these genes was similarly impacted using chromatin immunoprecipitation (ChIP) with antibodies that recognized acetylated lysines 9 and 14 on histone $\mathrm{H} 3\left(\mathrm{H} 3 \mathrm{~K} 9 / 14^{\mathrm{Ac}}\right)$, and primers that amplified 200 basepair fragments immediately upstream of the transcriptional start site of the genes studied above. We used H3K9/K14 ${ }^{\mathrm{Ac}}$ antibodies to capture acetylation of both H3K9 and H3K14 as our studies show these residues are targeted by Gcn 5 and Hda1. We assessed promoter acetylation in $g c n 5 \Delta$, $h d a 1 \Delta$ and $g c n 5 \Delta$ hda $\Delta 1$ mutants in the $a p c 5^{C A}$ background (Figure $3 \mathrm{~A}$ ). Antibodies against total $\mathrm{H} 3$ and a no antibody mock treatment were used as controls. The bands in all experiments were quantified and analyzed (Figure 3B). Once background densities were subtracted from all bands, the $\mathrm{H} 3 \mathrm{~K} 9 / 14^{\mathrm{Ac}} /$ total $\mathrm{H} 3$ ratio was determined. The values represent two independent experiments, as described previously [66,70]. H3 promoter acetylation was reduced in both $a p c 5^{C A} g c n 5 \Delta$ and $a p c 5^{C A} g c n 5 h d a 1 \Delta$ cells, similar to the transcript patterns at $37^{\circ} \mathrm{C}$ (Figure 2C), strengthening the notion that Gcn5 HAT activity is tightly correlated with transcription. However, it is interesting to note that while promoter acetylation is equally low in $a p c 5^{C A} g c n 5 \Delta$ cells at 30 and $37^{\circ} \mathrm{C}$, transcript defects are only obvious at $37^{\circ} \mathrm{C}$. Notably, a previous study observed that Gcn5-dependent transcription and promoter histone acetylation activities could be uncoupled [71].

Consistent with our observations that transcript levels of BCY1 and PDS1 increase in apc $5^{C A}$ hda1 $1 \Delta$ cells, we detected increased $B C Y 1$ and $P D S 1$ promoter acetylation in these cells, specifically at $37^{\circ} \mathrm{C}$. Transcript levels and promoter acetylation are both increased with PDS1 at $37^{\circ} \mathrm{C}$ in apc $5^{C A} h d a 1 \Delta$ cells. However, we note some differences in the patterns observed. For example, $B C Y 1$ transcripts are not elevated in $a p c 5^{C A}$ hda $1 \Delta$ cells at $37^{\circ}$ $\mathrm{C}$ while promoter acetylation is. This may reflect the complex nature of the factors assembled at promoters that is not addressed in this study.

\section{Gcn5 promoter occupancy increases in the absence of Hda1}

One possible scenario to explain increased PDS1 promoter acetylation and transcription in $a p c 5^{C A} h d a 1 \Delta$ cells 


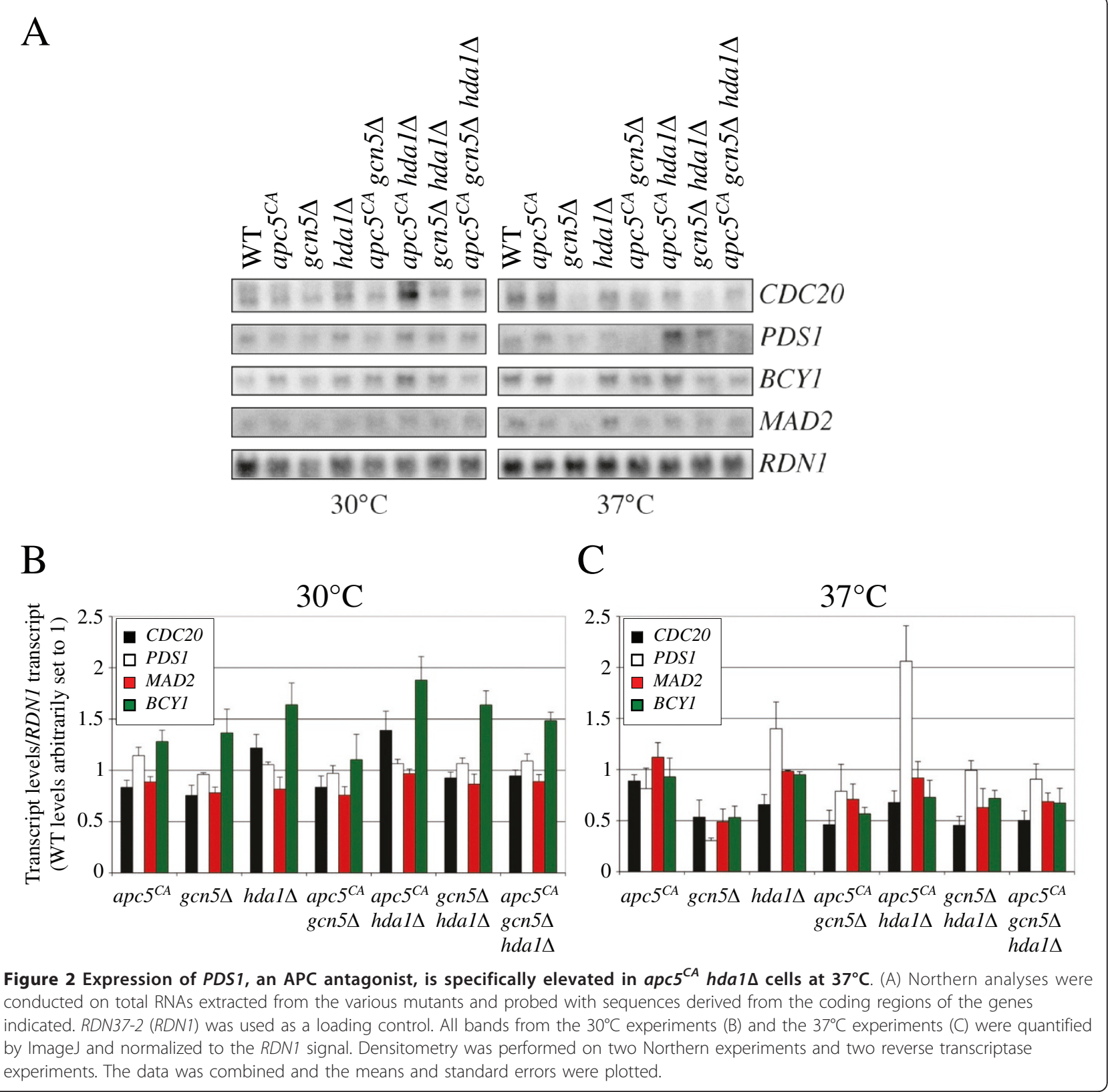

may be increased availability of Gcn 5 or related HATs due to the $a p c 5^{C A}$ allele. It was previously reported that in cells expressing defective TUP1, increased Gcn5 was observed at Tup1-repressible promoters, thereby derepressing transcription [40]. We have speculated that the APC may target Gcn5 for turnover in order to progress through the G1/S transition [57]. To examine this possibility, endogenous GCN5 was TAP-tagged in WT, $a p c 5^{C A}$ and apc10 $\Delta$ cells and detected by Westerns in asynchronous early log phase cells. Gcn 5 protein levels were indeed increased in both $a p c 5^{C A}$ and apc10 $\Delta$ cells (Figure 4A). While this does not explain the genetic interaction between $g c n 5 \Delta$ and $h d a 1 \Delta$ in $a p c 5^{C A}$ cells, it does suggest the possibility that a factor related to Gcn 5 may also be elevated in $a p c 5^{C A}$ cells. Consistent with this hypothesis, we observed increased Gcn5-HA and Elp3-HA, expressed from the GAL promoter, in cells lacking the proteasome ubiquitin receptor Rpn10 (Figure 4B). As controls, we TAP-tagged APC5 in rpn10D cells, which was unaffected by rpn10 $\Delta$. Furthermore, GAPDH

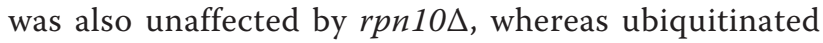
proteins did accumulate. Therefore, in cells lacking a functional ubiquitin system, at least Gcn5 and Elp3 accumulate. 


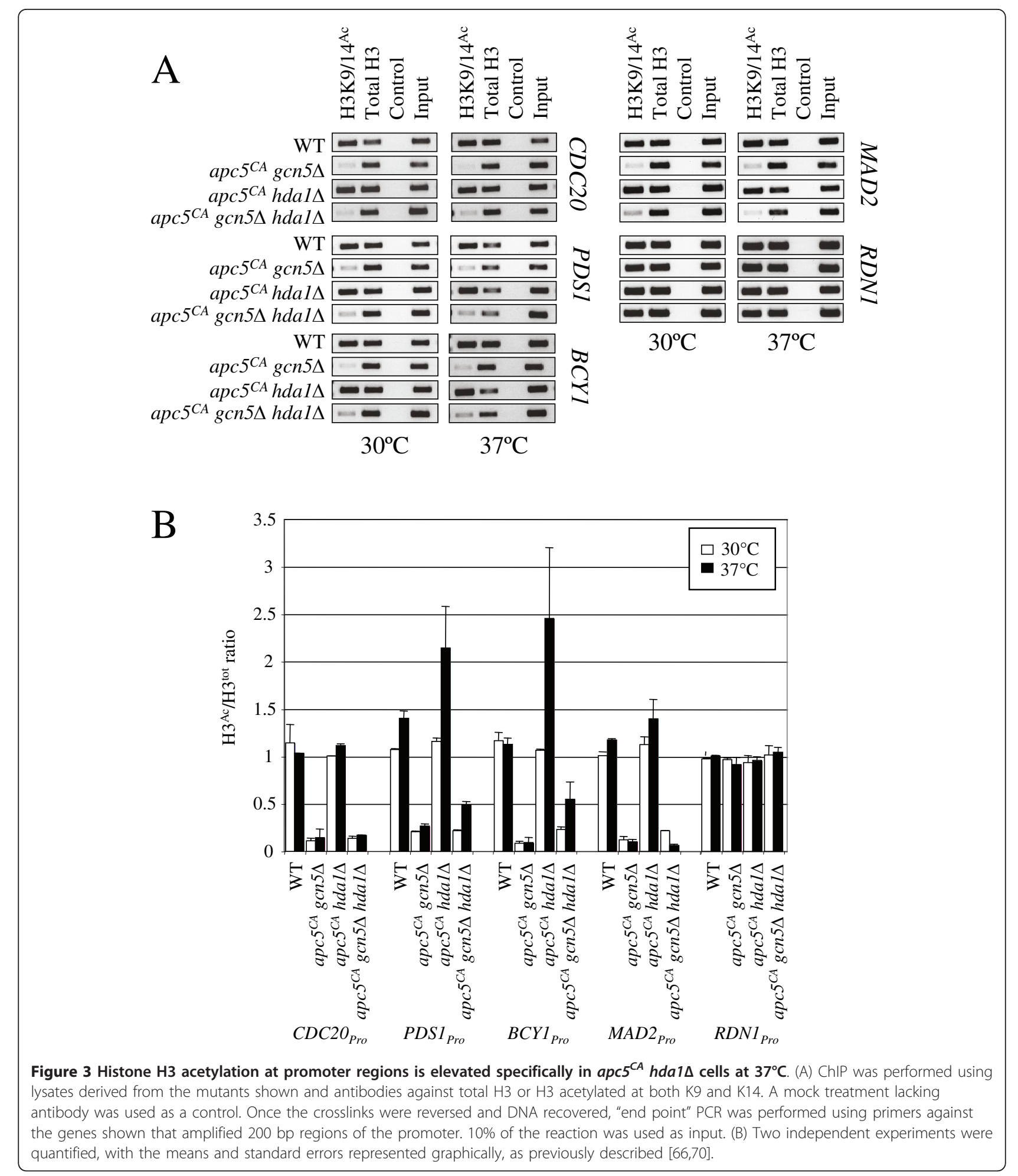

Next we asked whether promoter occupancy by Gcn 5 correlated with gene expression and promoter acetylation. GAL $L_{\text {pro }} G C N 5-H A$ was induced in $g c n 5 \Delta$ and $g c n 5 \Delta$ $h d a 1 \Delta$ cells so that the only Gcn 5 expressed was HA tagged. gcn5 $\Delta$ cells expressing $G A L_{\text {pro }} G C N 5-H A$ grew like WT (data not shown), and were considered the WT control for this experiment. ChIP was performed in lysates prepared from these cells. Control ChIPs were performed using untagged lysates (data not shown), and reactions without antibody, neither of which produced 
PCR products. Primers against the 5', middle, and 3' regions of $C D C 20$ demonstrated that Gcn5-HA recruitment was most prominent at the promoter and was reduced 5' to 3' (data not shown). We found that in $H D A 1$ cells expressing GCN5-HA, very little Gcn5-HA was present at the promoters tested compared with the $R D N 1$ promoter (Figures $4 \mathrm{C}$ and 4D). In hda1 $\mathrm{GCN5}$ $H A$ cells, however, increased Gcn5-HA promoter recruitment was observed. The increases observed were slight except for the $C D C 20$ promoter. Promoter acetylation also increased in hda1s cells, consistent with increased recruitment of Gcn5. These observations present the possibility that i) increased promoter $\mathrm{H} 3 \mathrm{~K} 9 / 14$ acetylation in $h d a 1 \Delta$ cells is due to increased Gcn5-HA promoter recruitment; and/or ii) Hda1 may block access of Gen5 to promoters.

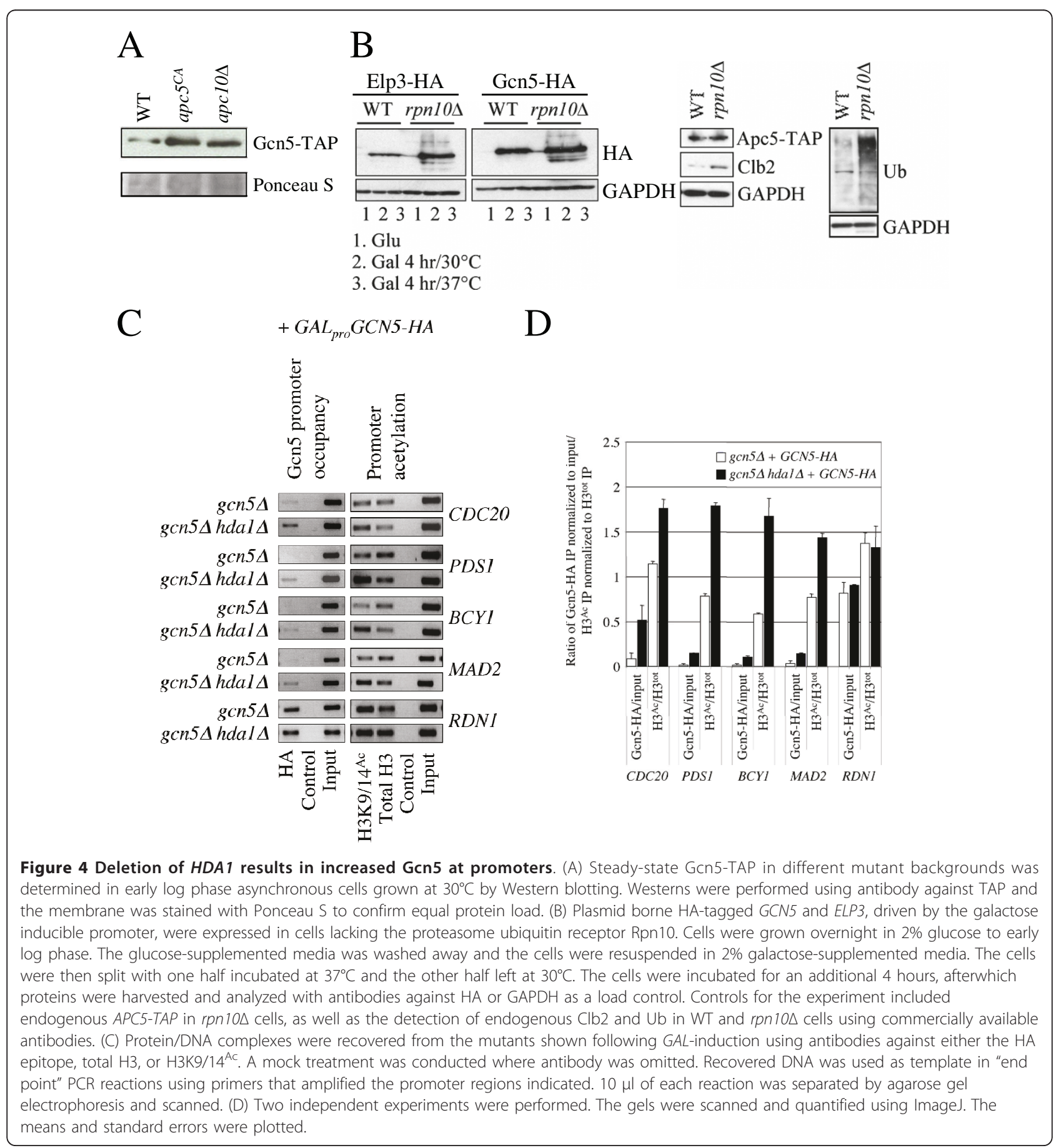


It is possible that increased Gcn5-HA recruitment is due to increased $G A L_{\text {pro }}$-driven Gcn5 expression in hda1 $\Delta$ cells, since Hda1 represses galactose-induced gene activation [72]. We assessed expression of Gcn5$\mathrm{HA}$ in the strains used above and observed that GALpro GCN5-HA expression after a 5 hour induction period was reduced in hda1 $\Delta$ cells (Figure 5A). Therefore, it is unlikely that the decreased levels of GAL-promoter driven $G C N 5$ in hda1D cells are due to Hda1's influence on the GAL promoter. Considering that hda1 $\Delta$ cells express less GCN5 than WT, yet recruit a greater amount of Gcn 5 to promoters, a much greater proportion of Gcn5-HA must be available for recruitment in $h d a 1 \Delta$ cells. To examine this possibility, we performed ChIP using lysates prepared from $G A L_{\text {pro }} G C N 5-H A$ expressing cells after 1, 3 and 5 hours of induction (Figure 5B). Gcn5-HA was recruited to each tested promoter (Figures 5C and 5D). When normalized to input, Gcn5-HA recruitment in HDA1 cells was similar at each induction timepoint (Figure 5D). In hda1s cells

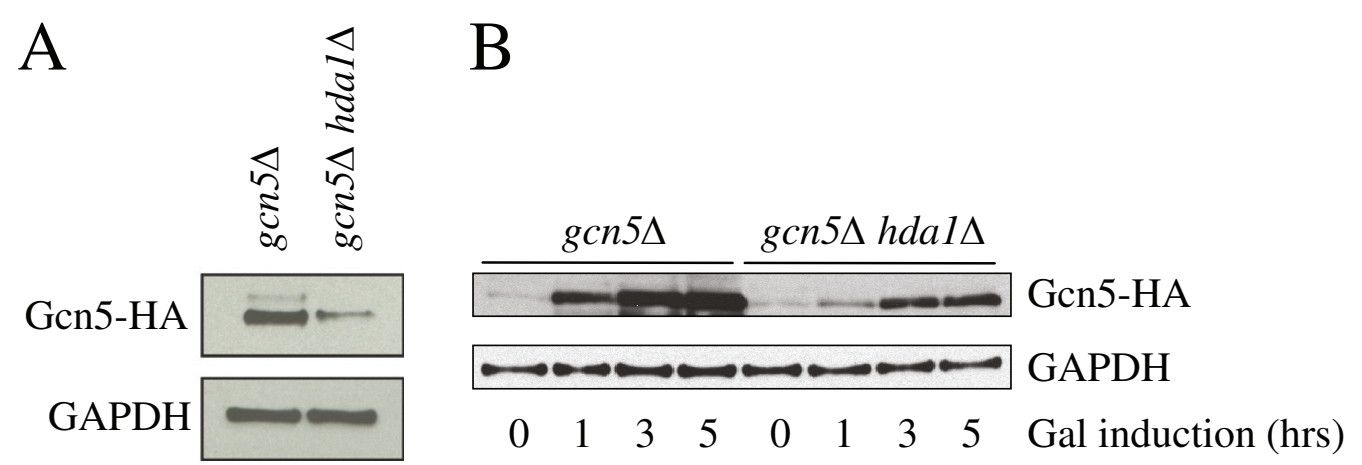

C

$$
+G A L_{p r o}-G C N 5-H A \quad g c n 5 \Delta
$$

gcn5 $\Delta$ hdal $\Delta$

$$
\text { S C I S C I S C I }
$$$$
\text { S C I S C I S C I }
$$
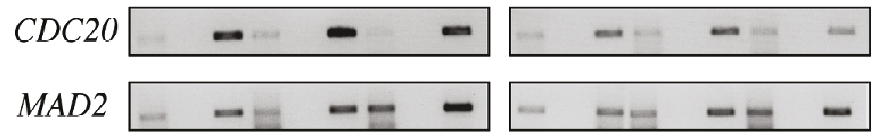

PDSI
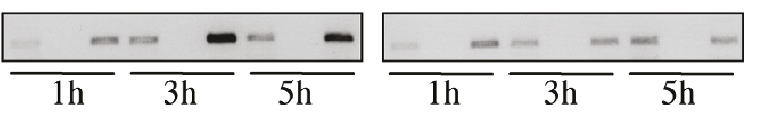

$\mathrm{D}$

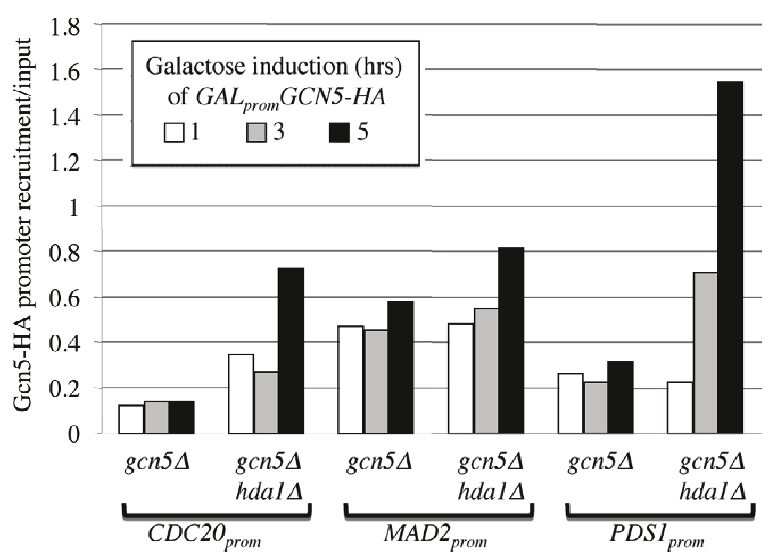

Figure 5 Gcn 5 promoter occupancy is kept at an equilibrium in WT cells, but increases over time in hda1 cells. (A) Western analyses of Gcn5-HA expression in gcn5 $\Delta$ and gcn5 $\Delta$ hda1 $\Delta$ cells following a 5 hour $4 \%$ galactose-induction. Antibodies against GAPDH were used as a load control. (B) A galactose-induction time-course was performed in gcn5 $\Delta$ and gcn5 $\Delta$ hda $1 \Delta$ cells expressing GAL pro-GCN5-HA. Protein samples were removed at the times shown for Western analyses with antibodies against HA and GAPDH. (C) From the time-course described above, samples were also removed for ChIP. Recovered DNA was used as a template in "end point" PCR reactions. S, sample with antibody; C, control without antibody; I, 10\% lysate input. (D) The gel in (C) was scanned, analyzed using ImageJ and plotted. 
however, Gcn5-HA recruitment was again increased, and recruitment increased the longer the induction. Together, our data suggests that in the absence of Hda1, Gcn5-HA continually gains access to the tested promoters.

\section{Tup1 occludes Gcn5 promoter occupancy}

We next tested whether the impact of Hda1 on Gcn5 promoter accessibility involved the corepressor complex Ssn6/Tup1. Several reports have demonstrated that the Ssn6/Tup1 corepressor utilizes Hda1 to repress transcription of target genes $[36,41,68]$. Furthermore, Tup1 has been shown to recruit Gcn 5 to repressed promoters
[73-75]. It was proposed that this may set the stage for derepression of silent genes. Thus, $G A L_{p r o} G C N 5-H A$ was induced in $h d a 1 \Delta$ and tup $1 \Delta$ cells as the only source of Gcn5, followed by ChIP. Gcn5-HA expression in hda1s cells was reduced compared to WT, but expression in tup $1 \Delta$ cells was unchanged (data not shown). We found that in otherwise WT strains ( gcn5 + GALproGCN5$H A$ ), Gcn5-HA was weakly recruited to the tested promoters (Figures $6 \mathrm{~A}$ and $6 \mathrm{~B}$ ). In strains lacking $H D A 1$ or TUP1, Gcn5-HA promoter occupancy was observed to increase. We also observed that in cells lacking SSN6, promoter recruitment of Gcn5-HA increased (data not shown). These results suggest that Hda1 may work
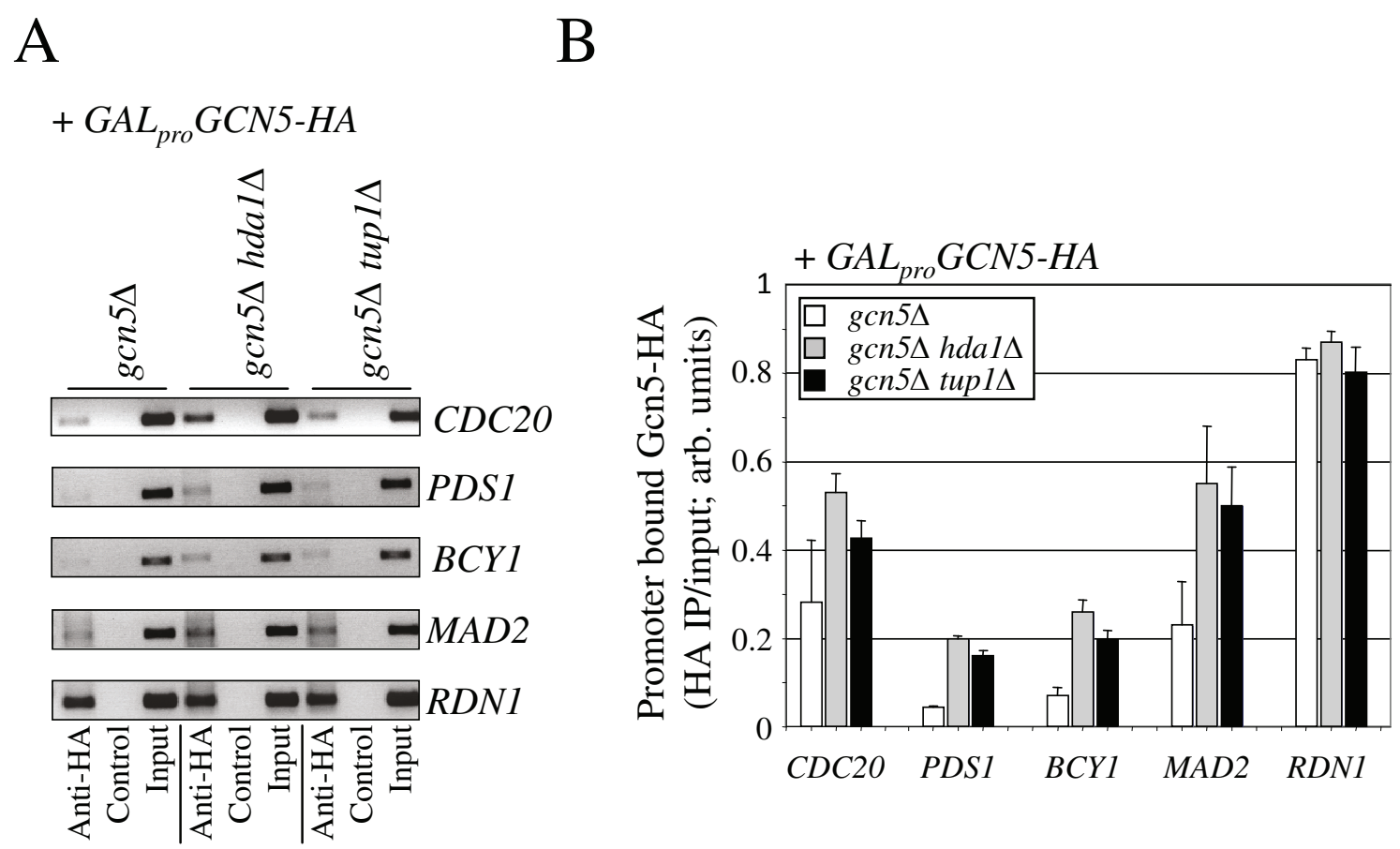

$\mathrm{C}$
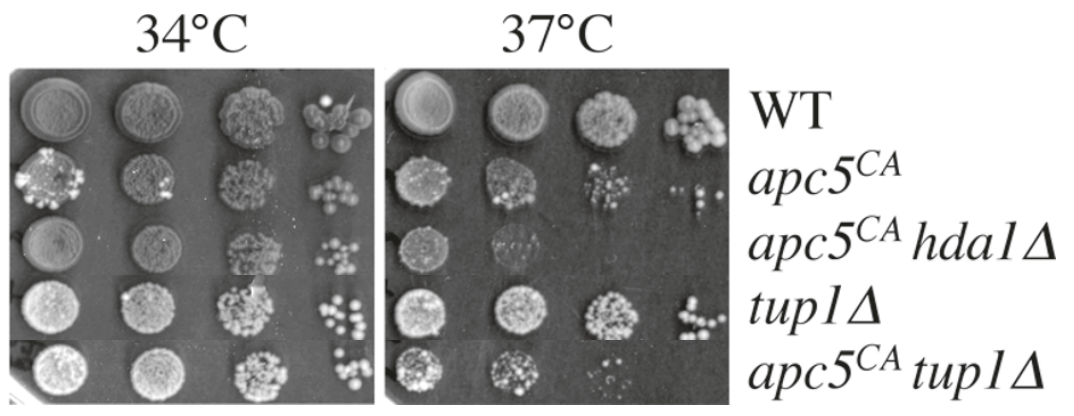

Figure 6 Tup1 occludes Gen5 recruitment. A) ChIP was performed using the cells shown expressing GAL pro-GCN5-HA following a 5 hour galactose induction, as described above. (B) Two independent experiments were scanned and processed using ImageJ, with the means and standard errors shown. (C) Strains lacking TUP1 were constructed in WT and apc5 ${ }^{C A}$ backgrounds. Growth phenotypes were assessed by spotdilutions, followed by incubation at $34^{\circ} \mathrm{C}$ and $37^{\circ} \mathrm{C}$. 
together with the Ssn6/Tup1 corepressor complex to impede access of Gcn 5 to the tested promoters. However, Hda1 and Gcn 5 may also compete for Tup1 interactions. It is also feasible that Tup1 utilizes different mechanisms to reduce Gcn5 promoter occupancy.

To distinguish between these possibilities, we predicted that if Tup1 and Hda1 work together, then deletion of TUP1 in apc $5^{C A}$ cells should have the same synergistic effects as an $H D A 1$ deletion. Our results show that deletion of TUP1 impairs the apc5 ${ }^{C A}$ phenotype (Figure $6 \mathrm{C}$ ), similar to an $h d a 1 \Delta$ mutation. This suggests that both Hda1 and Tup1 perform a function that is beneficial to APC activity. However, it does not necessarily indicate they work together to perform this task.

Hda1 and Tup1 likely interact at promoters, which can be inhibited by Gen5

Others have also shown Tup1 and Hda1 functionally interact to repress gene transcription $[36,41,68]$, and to associate in vitro [36], but not necessarily in vivo [46]. To investigate whether Tup1 and Hda1 do function together, we asked if Tup1 and Hda1 can physically interact at promoters, and if Gcn 5 can influence this. To do so we performed sequential ChIP in cells expressing a combination of Hda1-HA and/or GSTTup1. ChIP was first performed using antibodies against HA. Bound proteins were released, recovered, and incubated with antibodies against GST. Bound protein/DNA complexes were again isolated and PCR was performed using primers against the test promoters. The results show that in cells expressing either Hda1-HA or GST-Tup1, no bound DNA was recovered (Figure 7A and 7B). However, in cells co-expressing the plasmids, PCR fragments were obtained for all promoters tested. This supports the idea that Tup1 and Hda1 can associate in vivo at specific promoters. Nonetheless, this could also reflect close, but independent Hda1 and Tup1 binding on the same promoter.
A

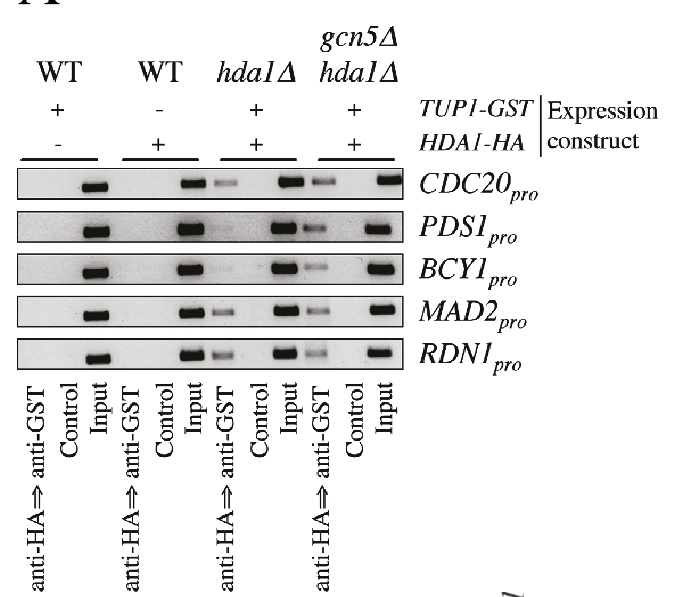

B

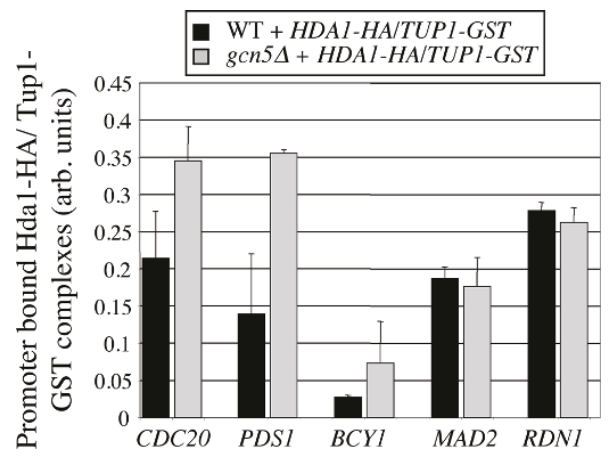

$\mathrm{C}$

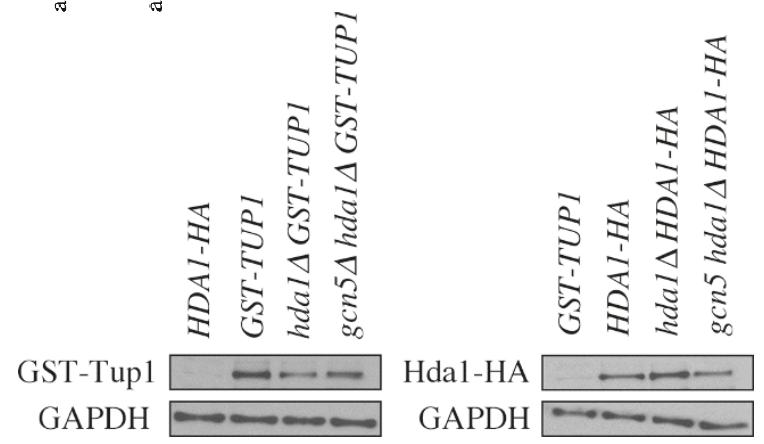

Figure 7 Gcn5 can inhibit Hda1-Tup1 associations at some promoters. (A) Sequential ChIP was used to observe Hda1-Tup1 physical interactions at specific promoters. WT, hdal $\triangle$ and gcn5 5 hdal $\triangle$ cells expressing combinations of GAL pro-HDA1-HA and CUP1 pro-TUP1-GST were induced using $4 \%$ galactose for 5 hours and $0.4 \mathrm{mM} \mathrm{CuSO}_{4}$ for 3 hours. ChIP reactions were first performed with antibodies against HA. Bound proteins were eluted from beads using $10 \mathrm{mM}$ DTT for 30 minutes at $37^{\circ} \mathrm{C}$. The eluted proteins were then incubated with anti-GST antibodies. The immune complexes were isolated again, cross links were reversed, and "end point" PCR was performed using the recovered DNA as template. (B) Two independent experiments were performed and processed using ImageJ. The means and standard errors are shown. (C) Westerns showing expression of the proteins used in the sequential ChIP experiment. 
In gcn5 $\Delta$ cells co-expressing the plasmids, putative complex formation was again observed, and was visibly increased at $C D C 20, P D S 1$, and $B C Y 1$ promoters, suggesting Gen 5 may negatively impact this interaction. Figure $7 \mathrm{C}$ shows that the proteins were expressed similarly in the strains used. Our experiments do not differentiate between Hda1 and Tup1 physically binding, or whether they simply bind adjacent DNA sequences, but it is important to note Hda1 and Tup1 were previously shown to physically associate [36], and that the interaction observed by sequential ChIP is enhanced by GCN5 deletion.

Taken together, the results presented in this report suggest a competitive interaction can occur between Hda1/Tup1 and Gcn5 at promoters (Figure 8). Our results suggest that the presence of Hda1/Tup1 (and likely Ssn6) occludes, at least partially, the recruitment of Gen 5 to some promoters. Gcn5, on the other hand, may impede Tup1-Hda1 interactions by competing for Tup1 binding. It is possible that the $g c n 5 \Delta / h d a 1 \Delta$ genetic interaction is prominent in $a p c 5^{C A}$ cells due to the accumulation of an APC target, perhaps another HAT, capable of suppressing gcn 5 hda $1 \Delta$ impairments.

\section{Discussion}

Novel Gcn5/Hda1 antagonistic functional interactions are revealed when APC activity is compromised

The work presented here provides evidence to support a model in which the HAT Gen5 and the HDAC Hda1 functionally interact at promoters to determine transcriptional readouts (Figure 8). In otherwise WT cells, mutations to GCN5 or HDA1 do not create significant growth defects, whereas in apc5 $5^{C A}$ cells, these same mutations produce severe $t$ s growth defects (Figure 1A). The focus of this study was to characterize an antagonistic functional $g c n 5 \Delta / h d a 1 \Delta$ interaction revealed in

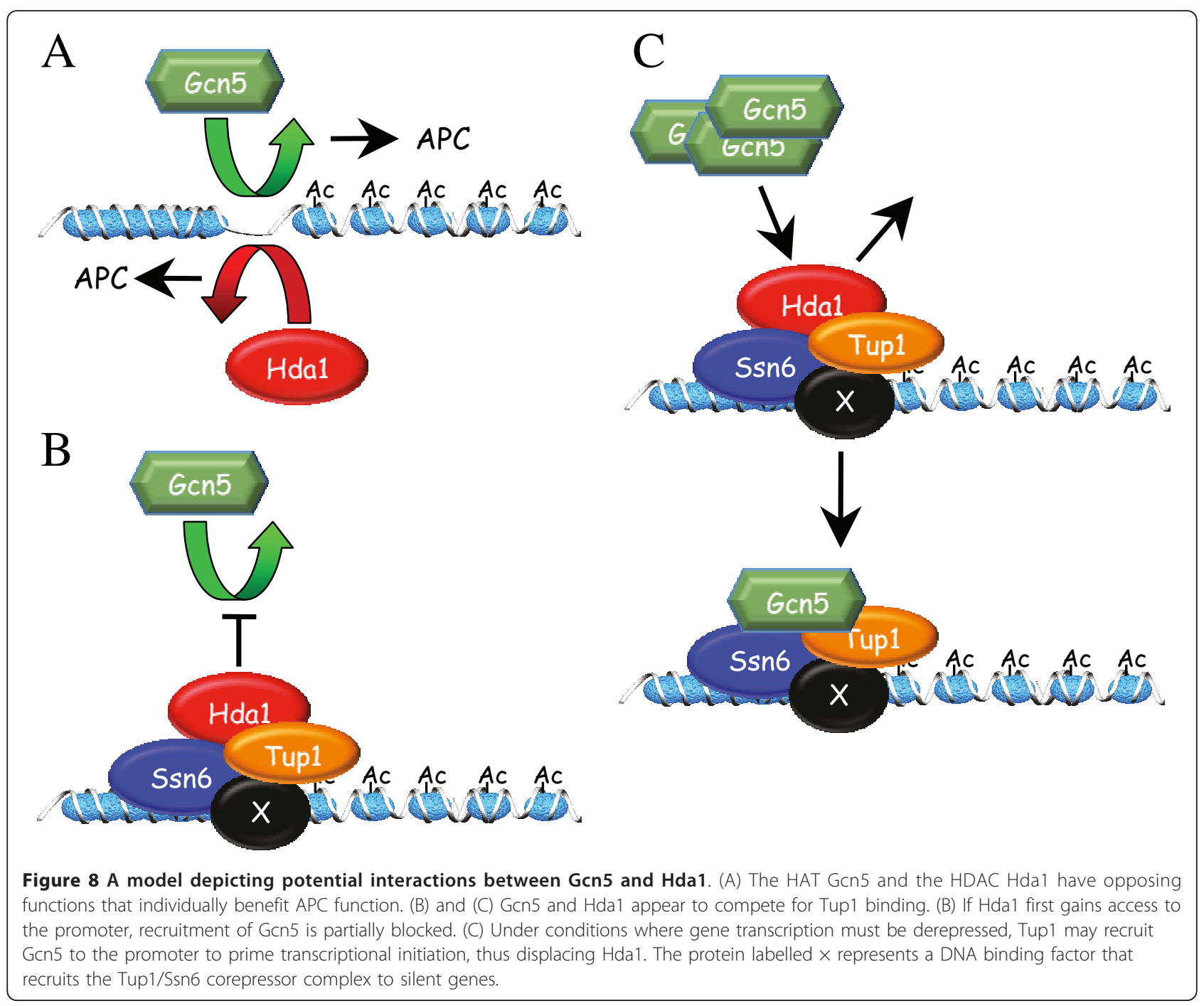


the $a p c 5^{C A}$ background, as the severe $a p c 5^{C A} g c n 5 \Delta$ and $a p c 5^{C A}$ hda $1 \Delta$ ts defects are suppressed in apc5 $5^{C A} g c n 5 \Delta$ hda1 $\Delta$ cells. Growth phenotypes associated with deletion of GCN5 have been shown in two separate Synthetic Genetic Array (SGA) genome-wide screens to be suppressed by deletion of $H D A 1$ [76,77]. However, spot dilution analysis of the $g c n 5 \Delta$ and $h d a 1 \Delta$ cells on YPD did not reveal any phenotypes [76], as shown in our study (Figure 1A). Thus, the gcn5 $\Delta d a 1 \Delta$ antagonistic interaction is not apparent under normal growth conditions, such as on YPD, but under conditions imposed by the SGA screen (selective media, for example), the antagonistic interaction can be exposed. The influence of the $a p c 5^{C A}$ allele on this interaction was investigated. The $a p c 5^{C A}$ allele had little effect on global histone $\mathrm{H} 3$ acetylation status in $g c n 5 \Delta$ and $h d a 1 \Delta$ cells, but did cause the increase of $B C Y 1$ and $P D S 1$ transcripts in hda1 $1 \Delta$ cells (Figures 1C, 3). Both Bcy1 and Pds1 proteins antagonize APC activity and may be involved in the enhanced growth defect when APC is mutated. Therefore, in apc $5^{C A}$ cells, it may be the inappropriate expression of inhibitory transcripts that are paramount to synergistic $a p c 5^{C A} g c n 5 \Delta$ and $a p c 5^{C A}$ hda $1 \Delta$ phenotypes.

A molecular mechanism explaining the Gcn5/Hda1 interaction likely involves competition for Tup 1 binding. We observed that in cells lacking HDA1 or TUP1, Gcn5 recruitment at our tested promoters was increased (Figures 4 and 6). On the other hand, deletion of GCN5 increased Hda1-Tup1 physical interactions at promoters (Figure 7). A competition between Hda1 and Gen5 for Tup1 binding is a possibility worth considering, as both Hda 1 and Gen 5 have been shown to physically interact with Tup1 [36,73-75]. However, in gcn5 hda1 $\Delta$ cells this mechanism would not be possible. In addition to the accumulation of Gcn5 in apc $5^{C A}$ cells, we observed that Elp3 also accumulates when the ubiquitin system is compromised (Figures 4A, B). We previously demonstrated that $g c n 5 \Delta$ and elp $3 \Delta$ deletions impair apc $5^{C A}$ defects, that GCN5 and ELP3 overexpression stalls the cell cycle in G1, and that Gcn5 G1-specific instability is reversed in APC mutants [57]. Thus, when $a p c 5^{C A}$ is combined with gcn5 $\Delta$ hda1 $\Delta$, an APC target likely accumulates that creates novel transcripts that allow bypass of the severe $t s$ defects observed in the double mutants. Elp3 is an attractive candidate since it is involved in elongating transcripts initiated by Gon 5 containing complexes [31]. A global transcript analysis is likely required to follow this further. Our previous work suggests that the $a p c 5^{C A}$ phenotype is sensitive to global transcript levels [57].

\section{Hda1-dependent occlusion of Gcn5 from promoters requires Tup1}

Several reports describe the recruitment of the Tup1/ Ssn6 repressor complex to DNA via interactions with multiple partners $[41,48,68]$. Once recruited, Tup1 then contacts $\mathrm{H} 3$ and $\mathrm{H} 4 \mathrm{~N}$-terminal tails [78]. Mechanisms employed to recruit Tup1/Ssn6 to promoters by the various individual interacting partners appears to be complex, seems to vary, and may have overlapping roles. Gcn5-HA recruitment to the tested promoters was increased in $h d a 1 \Delta$, tup $1 \Delta$ and $\operatorname{ssn} 6 \Delta$ cells (Figure 6; data not shown), indicating that the interaction of Hda1 with the Tup1/Ssn6 repressor complex is necessary to block access to Gen5. Tup1 and Hda1 did indeed coimmunoprecipitate while bound to the same promoters, as shown by sequential ChIP (Figure 7). We find it unlikely that Tup 1 and Hda1 are simply associating independently at adjacent sequences within the 200-basepair DNA PCR fragment, since they have been shown to interact previously [34], and are part of large complexes [19-23], but we cannot discount this possibility. However, we observed that in $g c n 5 \Delta$ cells, Hda1-Tup1 association increased at some promoters (PDS1 and BCY1), suggesting Gcn 5 opposes complex formation. The mechanism of action that Gcn5 uses to block Hda1Tup1 association remains unclear. Previous reports indicating that Tup1 is capable of recruiting and interacting with Gcn5/SAGA at promoters [73-75] suggest it is possible that Gcn5 and Hda1 may compete for Tup1 interaction. The scenario for recruiting either Gen 5 or Hda1 would differ, implying other proteins may be involved in deciding whether Gcn 5 or Hda1 gain access. We were unable to observe complex formation between Gcn5TAP and Hda1-HA in whole cell lysates (data not shown), indicating possible exchange of Gcn5 and Hda1 at Tup1 complexes does not require Gcn5-Hda1 association. It is also possible that Gen5-Hda1 physical interactions are transient and promoter specific, therefore may not be detectable using the methods applied here. Nonetheless, support for our model was provided by reports describing recruitment of Gcn 5 to promoters by the Tup1/Ssn6 complex under osmotic stress conditions $[40,74]$, indicating that Tup1/Ssn6 may be a transcriptional activator under certain conditions.

\section{Conclusions}

The results presented in this manuscript provide evidence for a complex network of interactions between a mitotic/G1 cell cycle regulator (the APC), and antagonistic interplay between a HAT (Gcn5), and an HDAC (Hda1). Gen5 is known to function during mitosis $[32,57,79,80]$. Data on the role Hda1 plays in cell cycle progression is limited, but Hda1 may provide some function to ensure histones are deacetylated prior to passage through mitosis [81]. It is noteworthy that Gcn5 and Hda1 expression is temporally regulated during the cell cycle (microarray data compiled at Saccharomyces Genome Database), providing insight into how the 
potential competition for Tup1 binding could be regulated. APC mutations cause cell cycle progression to stall during mitosis, potentially skewing the equilibrium between Gcn 5 and Hda1 promoter recruitment if the cell cycle does indeed influence Hda1 and Gcn5 recruitment. Future work will focus on identifying the molecular mechanisms regulating how cell cycle progression influences chromatin dynamics. Chromosome synthesis and segregation defects are widely associated with human disease, thus continued work into furthering our understanding of this process is vital.

\section{Methods}

Media, yeast strains, plasmids and general methods

Cells were grown in YPD (1\% yeast extract, $2 \%$ peptone, $2 \%$ glucose) or synthetic complete drop-out media (SD; $0.17 \%$ yeast nitrogen base, $0.5 \%\left(\mathrm{NH}_{4}\right)_{2} \mathrm{SO}_{4}, 2 \%$ glucose [or $4 \%$ galactose], $1.3 \mathrm{~g}$ amino acid drop-out powder/1 L, 1 tablet $\mathrm{NaOH}$ ). Genes under the control of the galactose promoter were induced with $4 \%$ galactose for 5 hours. All yeast strains were S288c derivatives unless mentioned otherwise (Table 1). Double and triple mutants were created by crossing appropriate strains, followed by multiple rounds of backcrossing. The strains used here were considered congenic. Some mutants, such as tup1 $\Delta$ (YTH3922), were created by one-step homologous recombination as previously described [54]. Primers flanking the TUP1 ORF by 500 basepairs were used in PCR reaction with genomic DNA from
YTH1449 as template. Colonies that grew on Geneticin (G418) were confirmed by PCR. GCN5 was TAP-tagged on the C-terminus using one-step homologous recombination. Primers designed to flank the GCN5 stop codon by 500 basepairs on either side were used in PRC reactions with genomic DNA isolated from YTH3864 as template. PCR fragments were then transformed into YTH1235 cells. Colonies that formed on SD-his plates were confirmed by PCR and Western analyses. Plasmids and sources used in this study are provided in Table 2. Yeast and E. coli transformations were done according to published procedures [54]. Overexpression from the CUP1 promoter was accomplished by adding $0.4 \mathrm{mM}$ $\mathrm{CuSO}_{4}$ to liquid growth media for 3 hours. Spot dilutions were performed by determining the $\mathrm{OD}_{600}$ of overnight cultures and then diluting the cells to $5 \times 10^{7} / \mathrm{ml}$. Ten-fold serial dilutions were prepared, with $3 \mu \mathrm{l}$ volumes of each dilution spotted onto the appropriate media and incubated at a variety of temperatures. Northerns and Westerns were performed as described previously $[54,60]$. Primers used in the Northern analyses are shown in Table 3. Rabbit polyclonal antiH3K9 ${ }^{\text {Ac }}$ (Upstate Biotechnology), rabbit monoclonal anti-H3K14 ${ }^{\text {Ac }}$ (Abcam), rabbit polyclonal anti-H3 (Abcam), rabbit polyclonal anti-HA (Abcam), and rabbit polyclonal anti-GST (Abcam) were used at 1:4000. Rabbit polyclonal anti-Clb2 (Santa Cruz; Y-180) and mouse monoclonal anti-ubiquitin (Cell Signalling Technology; P4D1) were used at 1:2000. The TAP antibody (Open

Table 1 Yeast strains used in this study

\begin{tabular}{|c|c|c|}
\hline Strains & Relevant genotype & Source \\
\hline YTH5 & MAT $\alpha$ ade2 his3 $\triangle 200$ lys $2 \Delta 201$ ura $3-52$ & {$[54]$} \\
\hline YTH1235 & MATa ade2 his3 $\triangle 200$ lys2 $\triangle 201$ ura3-52 & {$[60]$} \\
\hline YTH1449 & MATa his3 $\triangle 1$ leu2 $\triangle$ met15 $\triangle$ ura3 $\triangle$ tup $1 \triangle:: k a n M X 6$ & ResGen \\
\hline YTH1450 & MATa his3 $\triangle 1$ leu2 $\triangle$ met $15 \Delta$ ura3 $\triangle$ ssn6 $\triangle:$ :kanMX6 & ResGen \\
\hline YTH1235 & MATa ade2 his3 $\triangle 200$ lys2 $\triangle 201$ ura3-52 & {$[60]$} \\
\hline YTH1529 & 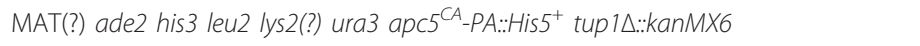 & This study \\
\hline YTH2305 & 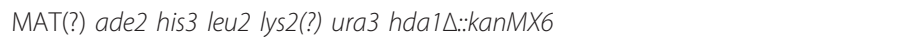 & {$[57]$} \\
\hline YTH2306 & 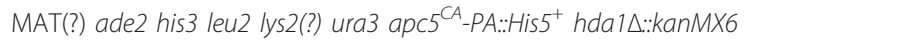 & {$[57]$} \\
\hline YTH3393 & MAT(?) ade2 his3 leu2 lys2(?) ura3 gen5ه::kanMX6 & This study \\
\hline YTH3395 & MAT(?) ade2 his3 leu2 lys2(?) ura3 apc5 ${ }^{C A}-P A: . H i s 5^{+}$gcn5 $:: k a n M X 6$ & This study \\
\hline YTH3477 & 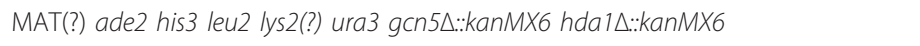 & This study \\
\hline YTH3480 & 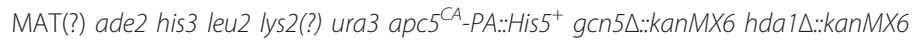 & This study \\
\hline YTH3638 & 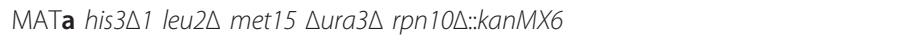 & ResGen \\
\hline YTH3864 & 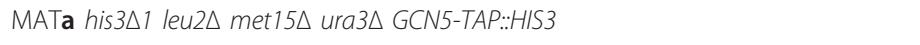 & ResGen \\
\hline YTH3883 & as YTH1235, with GCN5-TAP.:HIS3 & {$[57]$} \\
\hline YTH3922 & as YTH5, with tup $1 \triangle:: k a n M X 6$ & This study \\
\hline YTH3923 & as YTH5, with ssn6 $\triangle:: k a n M X 6$ & This study \\
\hline YTH4006 & MAT(?) ade2 his3 leu2 lys2(?) ura3 gcn5 & This study \\
\hline YTH4010 & 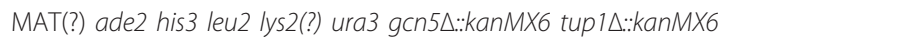 & This study \\
\hline YTH4379 & 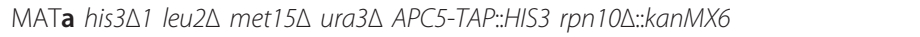 & This study \\
\hline
\end{tabular}

? denotes marker not determined. 
Table 2 Plasmids used in this study

\begin{tabular}{lll}
\hline Plasmid name & Markers/Integrated genes & Source \\
\hline YCp50 & URA3 CEN ARS & {$[54]$} \\
GAL pro-APC5-HA & $2 \mu$ GAL10 pro-APC5-HA URA3 & {$[57]$} \\
GAL pro-GCN5-HA & $2 \mu$ GAL10 pro-GCN5-HA URA3 & {$[57]$} \\
GAL pro-HDA1-HA & $2 \mu$ GAL10 pro-HDA1-HA URA3 & W. Xiao/ResGen \\
GAL pro-HPA2-HA & $2 \mu$ GAL10 pro-HDA1-HA URA3 & W. Xiao/ResGen \\
pGEX4T1-GST-TUP1 & $2 \mu$ CUP1 $1_{\text {pro-TUP1 URA3 }}$ & EXClone/Clontech \\
pGEX4T1-GST-SSN6 & $2 \mu$ CUP1 pro-TUP1 URA3 & ExClone/Clontech \\
\hline
\end{tabular}

Biosystems) was used at a dilution of 1:1000. Mouse monoclonal anti-GAPDH (Sigma) was used at a dilution of 1:20,000. Horseradish peroxidase (HRP)-conjugated secondary antibodies were used at dilution of 1:20,000 for GAPDH, and for all other antibodies 1:10,000, and detected by enhanced chemiluminescene (PerkinElmer).

\section{Reverse transcriptase PCR (rtPCR)}

Total RNA was treated with RNase-free DNase (Fermentas Life Sciences) following the manufacturer's recommendations. 1-5 $\mu \mathrm{g}$ of total RNA was used for cDNA synthesis using an oligo(dT) primer and M-MLV reverse transcriptase (Fermentas). RNA was incubated at $70^{\circ} \mathrm{C}$ for 10 minutes prior to the reverse transcriptase reaction. Finally, $1 \mu \mathrm{l}$ of each cDNA sample was used as template in PCR reactions with the primers described in Table 4 to amplify each of the target messages. To determine the PCR linear range for each message, $50 \mu \mathrm{l}$ PCR reactions were prepared using WT cDNA with each primer set (Table 3). $5 \mu$ l of each reaction was removed every 2 cycles, analyzed using 1\% agarose gel electrophoresis, and stained with ethidium bromide (data not shown). The gel was scanned and ImageJ was used to determine the mid-linear range cycle for each reaction. Subsequent $\mathrm{rtPCR}$ reactions were set up to cycle only to the predetermined mid-linear range. Primers that amplified the noncoding 18S rRNA RDN37-2, which is within the RDN1 locus (referred to as RDN1), were designed to generate a fragment for use as a control in Northerns and rtPCR.

\section{Chromatin immunoprecipitation (ChIP)}

ChIP was performed essentially as described elsewhere $[82,83]$ with the following modifications: DNA fragment

Table 3 Primers generated for the Northern analysis

\begin{tabular}{lll}
\hline Gene & Forward primer & Reverse primer \\
\hline CDC20 & 5'-TGCCAGAAAGCTCTAGAG & 5'-AACGAGAAGAGTATGCCG \\
PDS1 & 5'-TGATGCCAGCTAACGAAG & 5'-TTGTGGTAAGTCTGCATC \\
BCY1 & 5'-AATCGCAAGCCGAATTGC & 5'-TGGGTCCTCGTTCACAAAG \\
MAD2 & 5'-AGGGTTCAACAAGGACAG & 5'-GCACATTGAAGGACCATC \\
RDN1 & 5'-GGTGGAGTGATTGTCTG & 5'-ACGACGGAGTTCACAAG \\
\hline
\end{tabular}

Table 4 Primers generated for the ChIP analysis

\begin{tabular}{lll}
\hline Gene & Forward primer & Reverse primer \\
\hline CDC20 & 5'-CCGAAAGAGGCAAAACGT & 5'-TCTCTAGAGCTTTCTGGC \\
PDS1 & 5'-CACTATCACTTCCGTGC & 5'-CTTCGTTAGCTGGCATCA \\
BCY1 & 5'-GCAGAAGCCATAAGCTGA & 5'-GGGCAAAGAAGATACCATC \\
MAD2 & 5'-GCCATGCTGTTAATGTGGC & 5'-AAATGTGCTATTGGGCCC \\
RDN1 & 5'-TATGGTATGGTGACGGAG & 5'-CCACCTATTCCCTCTTGC \\
\hline
\end{tabular}

size achieved by sonication was $500-1000 \mathrm{bp}$, and $100 \mu \mathrm{g}$ of protein lysate was used for each IP. Protein concentration was determined by a Bradford protein assay. $5 \mu \mathrm{g}$ of ChIP grade rabbit polyclonal anti-acetyl-H3K9/14 (Upstate Biotechnology), rabbit polyclonal anti-H3 (Abcam), rabbit polyclonal HA antibody (Abcam), and rabbit polyclonal GST antibody (Abcam) were used for IP. One-tenth of the total volume of lysate was used as input for each sample. Sequential ChIP was performed as previously described [84]. In sequential ChIP experiements, the immune complexes were eluted by incubation for 30 minutes at $37^{\circ} \mathrm{C}$ in $10 \mathrm{mM}$ DTT. After centrifugation, the supernatant was diluted 25 times with ChIP dilution buffer (1\% Triton X-100, 2 mM EDTA, $150 \mathrm{mM}$ $\mathrm{NaCl}, 20 \mathrm{mM}$ Tris- $\mathrm{HCl}$ [pH 8.1]) and subjected again to ChIP using a different antibody. In this experiment, HA antibody was applied first, followed by GST antibody. Cross-linking of the immune complex was reversed by adding $\mathrm{NaCl}$ to a final concentration of $0.3 \mathrm{M}$ and incubated overnight at $65^{\circ} \mathrm{C}$. Samples were treated first with 1 $\mu \mathrm{g} / \mu \mathrm{l}$ RNaseA (Millipore [formerly Upstate]) for $30 \mathrm{~min}$ utes at $37^{\circ} \mathrm{C}$, followed by $1 \mu \mathrm{g} / \mu \mathrm{l}$ proteinase $\mathrm{K}$ (Millipore [formerly Upstate]) at $45^{\circ} \mathrm{C}$ for 1 hour. DNA was purified by chromatography on QIAquick columns, and eluted with elution buffer (PCR purification kit, Qiagen). PCR was performed for semiquantitative determination by standard end point PCR. $1 \mu$ I DNA was used for PCR, and the reaction continued to the predetermined midlinear range for each primer set. The end point PCR product was resolved on a $1 \%$ agarose gel and visualized by ethidium bromide. Two independent experiments were performed for each ChIP. The gel bands from each experiment were analyzed by ImageJ, and the means and standard error were plotted for graphical representation. For time course experiments, $200 \mathrm{ml}$ cultures were induced at a final concentration of $4 \%$ galactose. Samples $(20 \mathrm{ml})$ were immediately removed, and again after 1,3 and 5 hours. The $20 \mathrm{ml}$ samples were in duplicate for Western and ChIP analysis.

\footnotetext{
Acknowledgements

Al was supported by Post-Doctoral Fellowships from the Saskatchewan Health Research Foundation (SHRF), and from the Canadian Institutes for Health Research-Regional Partnership Program (CIHR-RPP). ELT was supported by Graduate Scholarships from the College of Graduate Studies at
} 
the $\mathrm{U}$ of S. Deletion mutants and plasmids were kindly provided by Dr. W. Xiao (University of Saskatchewan). We thank members of the Harkness lab, Ata Ghavidel and Spike Postnikoff, for careful reading of the manuscript and for providing insightful suggestions. Funding was generously provided to TAAH through a CIHR Operating Grant and a New Investigator Award from the Canadian Foundation for Innovation (CFI).

\section{Authors' contributions}

Al conducted the vast majority of the experiments described in this manuscript. ELT discovered the interaction between $a p c 5^{C A}, g c n 5 \Delta$ and hda1 $\triangle$ while performing the genetic screen designed to identify HAT and HDAC mutants that genetically interact with $a p c 5^{C A}$ [57]. ELT, MEM and JM contributed to work demonstrating accumulation of Gen5 and Elp3 in ubiquitin compromised strains. TAAH designed the study, supervised the work, and wrote the manuscript. All authors approve the final manuscript.

\section{Competing interests}

The authors declare that they have no competing interests.

Received: 20 January 2011 Accepted: 8 June 2011

Published: 8 June 2011

\section{References}

1. Tyler JK: Chromatin assembly. Cooperation between histone chaperones and ATP-dependent nucleosome remodeling machines. Eur J Biochem 2002, 269:2268-2274.

2. Verreault A: De novo nucleosome assembly: new pieces in an old puzzle. Genes Dev 2000, 14:1430-8.

3. Hagmann M: How chromatin changes its shape. Science 1999, 285:1200-1203.

4. Strahl $B D$, Allis CD: The language of covalent histone modifications. Nature 2000, 403:41-45

5. Brown CE, Lechner T, Howe L, Workman JL: The many HATs of transcription coactivators. Trends Biochem Sci 2000, 25:15-19.

6. Cheung WL, Briggs SD, Allis CD: Acetylation and chromosomal functions. Curr Opin Cell Biol 2000, 12:326-333.

7. Han Q, Lu J, Duan J, Su D, Hou X, Li F, Wang X, Huang B: Gcn5- and Elp3induced histone $\mathrm{H} 3$ acetylation regulates hsp70 gene transcription in yeast. Biochem J 2008, 409:779-788.

8. Sterner DE, Berger SL: Acetylation of histones and transcription-related factors. Microbiol Mol Biol Rev 2000, 64:435-459.

9. Struhl K: Histone acetylation and transcriptional regulatory mechanisms. Genes Dev 1998, 12:599-606.

10. Kurdistani SM, Grunstein M: Histone acetylation and deacetylation in yeast. Nat Rev Mol Cell Biol 2003, 4:276-284.

11. Paranjape SM, Kamakaka RT, Kadonaga JT: Role of chromatin structure in the regulation of transcription by RNA polymerase II. Annu Rev Biochem 1994, 63:265-297.

12. Krebs JE: Moving marks: dynamic histone modifications in yeast. Mol Biosyst 2007, 3:590-597.

13. Khan SN, Khan AU: Role of histone acetylation in cell physiology and diseases: An update. Clin Chim Acta 2010, 411:1401-1411.

14. Vogelauer M, Wu J, Suka N, Grunstein M: Global histone acetylation and deacetylation in yeast. Nature 2000, 408:495-498.

15. Kan PY, Lu X, Hansen JC, Hayes JJ: The H3 tail domain participates in multiple interactions during folding and self-association of nucleosome arrays. Mol Cell Biol 2007, 27:2084-2091.

16. Kan PY, Caterino TL, Hayes JJ: The $\mathrm{H} 4$ tail domain participates in intraand internucleosome interactions with protein and DNA during folding and oligomerization of nucleosome arrays. Mol Cell Biol 2009, 29:538-546.

17. Shogren-Knaak M, Ishii H, Sun JM, Pazin MJ, Davie JR, Peterson CL: Histone H4-K16 acetylation controls chromatin structure and protein interactions. Science 2006, 311:844-847.

18. Lucchini G, Hinnebusch AG, Chen C, Fink GR: Positive regulatory interactions of the HIS4 gene of Saccharomyces cerevisiae. Mol Cell Biol 1984, 4:1326-1333.

19. Brownell JE, Zhou J, Ranalli T, Kobayashi R, Edmondson DG, Roth SY, Allis CD: Tetrahymena histone acetyltransferase A: a transcriptional coactivator linking gene expression to histone acetylation. Cell 1996, 84:843-851.
20. Grant PA, Duggan L, Côté J, Roberts SM, Brownell JE, Candau R, Ohba R, Owen-Hughes T, Allis CD, Winston F, Berger SL, Workman JL: Yeast Gcn5 functions in two multisubunit complexes to acetylate nucleosomal histones: characterization of an Ada complex and the SAGA (Spt/Ada) complex. Genes Dev 1997, 11:1640-1650.

21. Baker SP, Grant PA: The SAGA continues: expanding the cellular role of a transcriptional co-activator complex. Oncogene 2007, 26:5329-5340.

22. Pray-Grant MG, Schieltz D, McMahon SJ, Wood JM, Kennedy EL, Cook RG, Workman JL, Yates JR, Grant PA: The novel SLIK histone acetyltransferase complex functions in the yeast retrograde response pathway. Mol Cell Biol 2002, 22:8774-8786.

23. Sendra R, Tse C, Hansen JC: The yeast histone acetyltransferase A2 complex, but not free Gcn5p, binds stably to nucleosomal arrays. J Biol Chem 2000, 275:24928-24934.

24. Johnsson AE, Wright AP: The role of specific HAT-HDAC interactions in transcriptional elongation. Cell Cycle 2010, 9:467-71.

25. McCullough SD, Grant PA: Histone acetylation, acetyltransferases, and ataxia-alteration of histone acetylation and chromatin dynamics is implicated in the pathogenesis of polyglutamine-expansion disorders. Adv Protein Chem Struct Biol 2010, 79:165-203.

26. Koutelou E, Hirsch CL, Dent SY: Multiple faces of the SAGA complex. Curr Opin Cell Biol 2010, 22:374-382.

27. Utley RT, Ikeda K, Grant PA, Cote J, Steger DJ, Eberharter A, John S, Workman JL: Transcriptional activators direct histone acetyltransferase complexes to nucleosomes. Nature 1998, 394:498-502.

28. Rosaleny LE, Ruiz-Garcia AB, Garcia-Martinez J, Perez-Ortin JE, Tordera V: The Sas3p and Gcn5p histone acetyltransferases are recruited to similar genes. Genome Biol 2007, 8:R119.

29. Bhaumik SR, Raha T, Aiello DP, Green MR: In vivo target of a transcriptional activator revealed by fluorescence resonance energy transfer. Genes Dev 2004, 18:333-343.

30. Wittschieben BO, Otero G, de Bizemont T, Fellows J, Erdjument-Bromage $H$, Ohba R, Li Y, Allis CD, Tempst P, Svejstrup JQ: A novel histone acetyltransferase is an integral subunit of elongating RNA polymerase II holoenzyme. Mol Cell 1999, 4:123-128.

31. Wittschieben BO, Fellows J, Du W, Stillman DJ, Svejstrup JQ: Overlapping roles for the histone acetyltransferase activities of SAGA and elongator in vivo. EMBO J 2000, 19:3060-3068.

32. Krebs JE, Fry CJ, Samuels ML, Peterson CL: Global role for chromatin remodeling enzymes in mitotic gene expression. Cell 2000, 102:587-598.

33. Wirén $M$, Silverstein RA, Sinha I, Walfridsson J, Lee HM, Laurenson P, Pillus L, Robyr D, Grunstein M, Ekwall K: Genome wide analysis of nucleosome density histone acetylation and HDAC function in fission yeast. EMBO $J$ 2005, 24:2906-2918.

34. Dubief MD, Sinha I, Billai FF, Bonilla C, Wright A, Grunstein M, Ekwall K: Specific functions for the fission yeast Sirtuins $\mathrm{Hst} 2$ and Hst4 in gene regulation and retrotransposon silencing. EMBO J 2007, 26:2477-2488.

35. Kurdistani SK, Robyr D, Tavazoie S, Grunstein M: Genome-wide binding map of the histone deacetylase Rpd3 in yeast. Nat Genet 2002, 31:248-254.

36. Wu J, Suka N, Carlson M, Grunstein M: TUP1 utilizes histone H3/H2Bspecific HDA1 deacetylase to repress gene activity in yeast. $\mathrm{Mol}$ Cell 2001, 7:117-126.

37. Robyr D, Suka Y, Xenarios I, Kurdistani SK, Wang A, Suka N, Grunstein M: Microarray deacetylation maps determine genome-wide functions for yeast histone deacetylases. Cell 2002, 109:437-446.

38. Komachi K, Redd M, Johnson A: The WD repeats of Tup1 interact with the homeo domain protein alpha 2. Genes Dev 1994, 8:2857-2867.

39. Tzamarias D, Struhl K: Distinct TPR motifs of Cyc8 are involved in recruiting the Cyc8-Tup1 corepressor complex to differentially regulated promoters. Genes Dev 1995, 9:821-831.

40. Kobayashi Y, Inai T, Mizunuma M, Okada I, Shitamukai A, Hirata D, Miyakawa T: Identification of Tup1 and Cyc8 mutations defective in the responses to osmotic stress. Biochem Biophys Res Commun 2008, 368:50-55.

41. Zhang Z, Reese JC: Redundant Mechanisms Are Used by Ssn6-Tup1 in Repressing Chromosomal Gene Transcription in Saccharomyces cerevisiae. J Biol Chem 2004, 279:39240-39250.

42. Bone JR, Roth SY: Recruitment of the yeast Tup1p-Ssn6p repressor is associated with localized decreases in histone acetylation. $J$ Biol Chem 2001, 276:1808-1813. 
43. Deckert J, Struhl K: Histone acetylation at promoters is differentially affected by specific activators and repressors. Mol Cell Biol 2001 21:2726-2735.

44. Davie JK, Trumbly RJ, Dent SY: Histone-dependent association of Tup1Ssn6 with repressed genes in vivo. Mol Cell Biol 2002, 22:693-703.

45. Watson AD, Edmondson DG, Bone JR, Mukai Y, Yu Y, Du W, Stillman DJ, Roth SY: Ssn6-Tup1 interacts with class I histone deacetylases required for repression. Genes Dev 2000, 14:2737-2744.

46. Davie JK, Edmondson DG, Coco CB, Dent SY: Tup1-Ssn6 interacts with multiple class I histone deacetylases in vivo. J Biol Chem 2003, 278:50158-50162.

47. Smith RL, Johnson AD: Turning genes off by Ssn6-Tup1: a conserved system of transcriptional repression in eukaryotes. Trends Biochem Sci 2000, 25:325-330.

48. Malavé TM, Dent SY: Transcriptional repression by Tup1-Ssn6. Biochem. Cell Biol 2006, 84:437-443.

49. Harper JW, Burton JL, Solomon MJ: The anaphase-promoting complex: it's not just for mitosis any more. Genes Dev 2002, 16:2179-2206.

50. Manchado E, Eguren M, Malumbres M: The anaphase-promoting complex/ cyclosome (APC/C): cell-cycle-dependent and -independent functions. Biochem Soc Trans 2010, 38:65-71.

51. Buchakjian MR, Kornbluth S: The engine driving the ship: metabolic steering of cell proliferation and death. Nat Rev Mol Cell Biol 2010, 11:715-27.

52. Qiao X, Zhang L, Gamper AM, Fujita T, Wan Y: APC/C-Cdh1: from cell cycle to cellular differentiation and genomic integrity. Cell Cycle 2010, 9:3904-12.

53. Arnason TG, Pisclevich MG, Dash MD, Davies GF, Harkness TA: Novel interaction between Apc5p and Rsp5p in an intracellular signaling pathway in Saccharomyces cerevisiae. Eukaryot Cell 2005, 4:134-146.

54. Harkness TA, Davies GF, Ramaswamy V, Arnason TG: The ubiquitindependent targeting pathway in Saccharomyces cerevisiae plays a critical role in multiple chromatin assembly regulatory steps. Genetics 2002, 162:615-632.

55. Harkness TA, Arnason TG, Legrand C, Pisclevich MG, Davies GF, Turner EL: Contribution of CAF-I to anaphase-promoting-complex-mediated mitotic chromatin assembly in Saccharomyces cerevisiae. Eukaryot Cell 2005, 4:673-684.

56. Harkness TA: Chromatin assembly from yeast to man: Conserved factors and conserved molecular mechanisms. Curr Genomics 2005, 6:227-240.

57. Turner EL, Malo ME, Pisclevich MG, Dash MD, Harkness TA: The Anaphase Promoting Complex interacts with multiple histone modifying enzymes to regulate cell cycle progression in yeast. Eukaryot Cell 2010, 9:1418-1431.

58. Kotani S, Tanaka H, Yasuda H, Todokoro K: Regulation of APC Activity by Phosphorylation and Regulatory Factors. J Cell Biol 1998, 146:791-800.

59. Rudner AD, Murray AW: Phosphorylation by Cdc28 activates the Cdc20dependent activity of the anaphase-promoting complex. J Cell Biol 2000, 149:1377-1390.

60. Harkness TA, Shea KA, Legrand C, Brahmania M, Davies GF: A functional analysis reveals dependence on the anaphase-promoting complex for prolonged life span in yeast. Genetics 2004, 168:759-774

61. Nasmyth K: How do so few control so many? Cell 2005, 120:739-746.

62. Suijkerbuijk SJ, Kops GJ: Preventing aneuploidy: the contribution of mitotic checkpoint proteins. Biochim Biophys Acta 2008, 1786:24-31.

63. Simonetta M, Manzoni R, Mosca R, Mapelli M, Massimiliano L, Vink M, Novak B, Musacchio A, Ciliberto A: The influence of catalysis on mad2 activation dynamics. PLOS Biol 2009, 7:e10.

64. Benhamed M, Bertrand C, Servet C, Zhou DX: Arabidopsis GCN5, HD1, and TAF1/HAF2 interact to regulate histone acetylation required for lightresponsive gene expression. Plant Cell 2006, 18:2893-2903.

65. Vetting MW, Magnet S, Nieves E, Roderick SL, Blanchard JS: A bacterial acetyltransferase capable of regioselective $\mathrm{N}$-acetylation of antibiotics and histones. Chem Biol 2004, 11:565-573.

66. Landry J, Sutton A, Tafrov ST, Heller RC, Stebbins J, Pillus L, Sternglanz R: The silencing protein SIR2 and its homologs are NAD-dependent protein deacetylases. Proc Natl Acad Sci USA 2000, 97:5807-5811.

67. Vogelauer M, Wu J, Suka N, Grunstein M: Global histone acetylation and deacetylation in yeast. Nature 2000, 408:495-498.

68. Green SR, Johnson AD: Promoter-dependent roles for the Srb10 cyclindependent kinase and the Hda1 deacetylase in Tup1-mediated repression in Saccharomyces cerevisiae. Mol Biol Cell 2004, 15:4191-4202.
69. Lee TI, Causton HC, Holstege FC, Shen WC, Hannett N, Jennings EG, Winston F, Green MR, Young RA: Redundant roles for the TFIID and SAGA complexes in global transcription. Nature 2000, 405:701-704.

70. Koç A, Wheeler LJ, Mathews CK, Merrill GF: Replication-independent MCB gene induction and deoxyribonucleotide accumulation at G1/S in Saccharomyces cerevisiae. J Biol Chem 2003, 278:9345-9352.

71. Imoberdorf RM, Topalidou I, Strubin M: A role for gen5-mediated global histone acetylation in transcriptional regulation. Mol Cell Biol 2006, 26:1610-1616

72. Larschan E, Winston F: The Saccharomyces cerevisiae Srb8-Srb11 complex functions with the SAGA complex during Gal4-activated transcription Mol Cell Biol 2005, 25:114-123.

73. Papamichos-Chronakis M, Petrakis T, Ktistaki E, Topalidou I, Tzamarias D: Cti6, a PHD domain protein, bridges the Cyc8-Tup1 corepressor and the SAGA coactivator to overcome repression at GAL1. Mol Cell 2002, 9:1297-1305.

74. Proft M, Struhl K: Hog1 kinase converts the Sko1-Cyc8-Tup1 repressor complex into an activator that recruits SAGA and SWI/SNF in response to osmotic stress. Mol Cell 2002, 9:1307-1317.

75. DeSimone AM, Laney JD: Corepressor-directed preacetylation of histone $\mathrm{H} 3$ in promoter chromatin primes rapid transcriptional switching of celltype-specific genes in yeast. Mol Cell Biol 2010, 30:3342-3356.

76. Lin YY, Qi Y, Lu JY, Pan X, Yuan DS, Zhao Y, Bader JS, Boeke JD: A comprehensive synthetic genetic interaction network governing yeast histone acetylation and deacetylation. Genes Dev 2008, 22:2062-2074.

77. Costanzo M, Baryshnikova A, Bellay J, Kim Y, Spear ED, Sevier CS, Ding H, Koh JL, Toufighi K, Mostafavi S, Prinz J, St Onge RP, VanderSluis B, Makhnevych T, Vizeacoumar FJ, Alizadeh S, Bahr S, Brost RL, Chen Y, Cokol M, Deshpande R, Li Z, Lin ZY, Liang W, Marback M, Paw J, San Luis BJ, Shuteriqi E, Tong AH, van Dyk N, Wallace IM, Whitney JA, Weirauch MT, Zhong G, Zhu H, Houry WA, Brudno M, Ragibizadeh S, Papp B, Pál C, Roth FP, Giaever G, Nislow C, Troyanskaya OG, Bussey H, Bader GD, Gingras AC, Morris QD, Kim PM, Kaiser CA, Myers CL, Andrews BJ Boone C: The genetic landscape of a cell. Science 2010, 327:425-431.

78. Edmondson DG, Smith MM, Roth SY: Repression domain of the yeast global repressor Tup1 interacts directly with histones $\mathrm{H} 3$ and $\mathrm{H} 4$. Genes Dev 1996, 10:1247-1259.

79. Fillingham J, Recht J, Silva AC, Suter B, Emili A, Stagljar I, Krogan NJ, Allis CD, Keogh MC, Greenblatt JF: Chaperone control of the activity and specificity of the histone $\mathrm{H} 3$ acetyltransferase Rtt109. Mol Cell Biol 2008, 28:4342-4353.

80. Vernarecci S, Ornaghi P, Bâgu A, Cundari E, Ballario P, Filetici P: Gcn5p plays an important role in centromere kinetochore function in budding yeast. Mol Cell Biol 2008, 28:988-996.

81. Kanta $H$, Laprade L, Almutairi A, Pinto I: Suppressor analysis of a histone defect identifies a new function for the hda1 complex in chromosome segregation. Genetics 2006, 173:435-450.

82. Rundlett SE, Carmen AA, Suka N, Turner BM, Grunstein M: Transcriptional repression by UME6 involves decaetylation of lysine 5 of histone $\mathrm{H} 4$ by RPD3. Nature 1998, 392:831-835.

83. Suka N, Nakashima E, Shinmyozu K, Hidaka M, Jingami H: The WD40-repeat protein Pwp1p associates with $25 \mathrm{~S}$ ribosomal chromatin in a histone $\mathrm{H} 4$ tail-dependent manner. Nucleic Acid Res 2006, 34:3555-3567.

84. Schnekenburger $M$, Peng L, Puga A: HDAC1 bound to the Cyp1a1 promoter blocks histone acetylation associated with Ah receptormediated trans-activation. Biochim Biophys Acta 2007, 1769:569-578.

doi:10.1186/1747-1028-6-13

Cite this article as: Islam et al:: Antagonistic Gcn5-Hda1 interactions revealed by mutations to the Anaphase Promoting Complex in yeast. Cell Division 2011 6:13. 